\title{
Further Observations on Use of D-Penicillamine in Cystinuria
}

\author{
J. C. CRAWHALL, * PH.D., M.B., B.S ; E. F. SCOWEN, $†$ M.D., D.SC., F.R.C.P., F.R.C.S. \\ R. W. E. WATTS, $\ddagger$ M.D., PH.D., M.R.C.P.
}

Brit. med. F., 1964, 1, 1411-1413

It was shown in a previous communication (Crawhall et al., 1963) that the abnormally high level of cystine excretion found in homozygotes for cystinuria could be reduced for short periods by the administration of $\mathrm{D}$-penicillamine. This paper reports the results of administering the drug continuously to a group of cystinuric patients for periods of five months to one year.

We have used the $\mathrm{D}$-isomer of penicillamine rather than the racemic (DL) mixture because L-penicillamine antagonizes pyridoxal phosphate and is known to be toxic in experimental animals (Aposhian and Aposhian, 1959). Continuous treatment with D-penicillamine has been used in other diseases, and no serious toxic effects have been reported. Rash, fever, lymphadenopathy, and leucopenia sometimes occur soon after the beginning of treatment but can be overcome by the administration of anti-inflammatory steroids for short periods (Scheinberg and Sternlieb, 1960). Goldberg et al. (1963) reported proteinuria in a patient with chronic lead-poisoning who was treated with D-penicillamine, and Walshe (1960) observed that a patient who was allergic to penicillin was abnormally sensitive to penicillamine. Levine (1960) noted cutaneous cross-sensitivity reactions to penicillin, benzylpenicilloic acid, and penicillamine.

We have previously reported chromatographic evidence for the presence of L-cysteine-D-penicillamine in the urine of cystinuric patients taking $\mathrm{D}$-penicillamine (Crawhall et al., 1963). This substance has now been synthesized and purified. Its solubility properties have been studied, and it has been shown to be identical with the new disulphide which appears in the urine of cystinuric patients taking D-penicillamine.

\section{Methods and Materials}

The methods of gravimetric and paper chromatographic analysis of cystinuric urine have been previously described (Crawhall et al., 1963). These results have been confirmed by automatic amino-acid analysis (Technicon Instruments), and details of this method will be published elsewhere. L-cysteine hydrochloride was obtained from L. Lights \& Co., D-penicillamine hydrochloride from Dista Products Ltd., and L- $\left[{ }^{35} \mathrm{~S}\right]-$ cystine from the Radiochemical Centre, Amersham. All the results shown in Table $I$ are the average of three or more determinations of 24-hour cystine excretions.

Synthesis of L-cysteine-D-penicillamine Mixed Disulphide.L-cysteine hydrochloride (1.5 g., $9.6 \mathrm{mmole})$ and D-penicillamine hydrochloride ( $330 \mathrm{mg}$., $1.8 \mathrm{mmole}$ ) were dissolved in ammonium

TABle I.-Effect of D-penicillamine on Cystine Excretion (mg./24 hours)

\begin{tabular}{|c|c|c|c|c|c|c|c|}
\hline \multirow{2}{*}{$\begin{array}{l}\text { Case } \\
\text { No. }\end{array}$} & \multicolumn{7}{|c|}{ Dose of Penicillamine Hydrochloride } \\
\hline & Control & $\begin{array}{c}150 \mathrm{mg} . \\
\text { 8-hrly. }\end{array}$ & $\begin{array}{l}300 \text { mg. } \\
\text { 8-hrly. }\end{array}$ & $\begin{array}{r}2 \times 300 \mathrm{mg} \\
+450 \mathrm{mg} \\
\end{array}$ & $\begin{array}{l}450 \mathrm{mg} . \\
\text { 8-hrly. }\end{array}$ & $\begin{array}{c}600 \mathrm{mg} . \\
8 \text {-hrly. }\end{array}$ & $\begin{array}{c}900 \mathrm{mg} . \\
\text { 8-hrly. }\end{array}$ \\
\hline $\begin{array}{l}2 \\
3 \\
4 \\
5 \\
6 \\
7\end{array}$ & $\begin{array}{c}740 \\
940 \\
1,420^{*} \\
480 \\
340 \\
460\end{array}$ & $\begin{array}{l}290 \\
220\end{array}$ & $\begin{array}{l}490 \\
580 \\
\\
240 \\
290 \\
120\end{array}$ & 160 & 240 & $\begin{array}{r}240 \\
260 \\
370 \\
60\end{array}$ & $\begin{array}{r}10 \\
20 \\
200\end{array}$ \\
\hline
\end{tabular}

* This value was obtained by isotope dilution. The other values were obtained by gravimetric analysis. hydroxide ( $4 \mathrm{~N}, 20 \mathrm{ml}$.$) . Ferric chloride (0.2 \mathrm{ml} ., 5 \% \mathrm{w} / \mathrm{v}$ in water) was added. Air was drawn through this solution for 18 hours via a wash-bottle also containing ammonium hydroxide $(4 \mathrm{~N})$. The precipitated cystine and ferric hydroxide were removed by centrifugation and water was removed from the supernatant solution by evaporation in a rotary evaporator at $30^{\circ} \mathrm{C}$. The residue was leached with water $(2 \times 25 \mathrm{ml}$. $)$ and the washings were applied to an ion-exchange chromatographic column (" amberlite CG 120 " in the $\mathrm{H}^{+}$form ; $12 \times$ $250 \mathrm{~mm}$. The column was eluted with water $(200 \mathrm{ml}$.) followed by ammonium hydroxide $(2 \mathrm{~N}, 250 \mathrm{ml}$.). The ammonia was removed by evaporation in a rotary evaporator at $30^{\circ} \mathrm{C}$., leaving a solid residue of the mixed disulphide (204 mg.) contaminated with a small quantity of cystine and penicillamine disulphide. The residue was recrystallized three times from hot water to yield the pure mixed disulphide.

(Found: C, $36.0 ; \mathrm{H}, 5.9 ; \mathrm{N}, 10.5 ; \mathrm{S}, 23.8$. $\mathrm{C}_{8} \mathrm{H}_{26} \mathrm{~N}_{2} \mathrm{O}_{4} \mathrm{~S}_{2}$ requires $\mathrm{C} 35.8 ; \mathrm{H}, 6.0 ; \mathrm{N}, 10.4 ; \mathrm{S}, 23.9 \%$.) The solubility of this compound was $1 \%$ at $37^{\circ} \mathrm{C}$., and it gave only one ninhydrin positive spot on thin-layer chromatography (silica gel (Merck) with gypsum. eluant-phenol: 15\% aqueous formic acid, $75: 25$ ).

$\mathrm{D}$-penicillamine disulphide was synthesized as described by Clarke et al. (1949).

\section{Clinical Studies}

Case 1.-The 11-year-old girl previously recorded as Case 2 by Crawhall et al. (1963) had had repeated episodes of renal colic and two left nephrolithotomies. D-penicillamine hydrochloride has been administered eight-hourly $(300 \mathrm{mg}$. at $7 \mathrm{a} . \mathrm{m}$. and at $3 \mathrm{p} . \mathrm{m}$. and $450 \mathrm{mg}$. at 11 p.m.) for one year. She has remained in good health, has grown normally, and continues to excrete less than $100 \mathrm{mg}$. of cystine per 24 hours.

Case 2.-A woman aged 39 had had eight episodes of renal colic, the first of which occurred when she was 13 years old. Four of these had required admission to hospital. She had a left ureterolithotomy and right pyelolithotomy when she was 23 and a right ureterolithotomy at the age of 25 . There was no family history of renal disease, and she excreted about $700 \mathrm{mg}$. of cystine per 24 hours before treatment was begun. Headache, sore throat, malaise, mild fever, and a generalized irritant morbilliform rash developed on the ninth day of treatment with D-penicillamine. The eruption progressed to a mild exfoliative phase despite the use of promethazine hydrochloride (25 mg. eight-hourly), and a mild eosinophilia was observed. There was no previous history of abnormal sensitivity to drugs or other agents. Penicillamine treatment was discontinued and we did not attempt to reinstate it. The excretion of L-cysteineD-penicillamine mixed disulphide and D-penicillamine disulphide continued for two days after the administration of D-penicillamine was stopped.

Case 3.-A man aged 29 had previously been a merchant seaman in the tropics and had had repeated episodes of calculus formation for 13 years. These were initially right-sided, and a right nephrec-

* Lecturer in Medicine, Medical Professorial Unit, St. Bartholomew's Hospital, London.

† Professor of Medicine, Medical Professorial Unit, St. Bartholomew's Hospital, London.

‡ Senior Lecturer in Medicine, Medical Professorial Unit, St. Bartholomew's Hospital, London. 
tomy had been performed seven years previously. He has since passed more calculi with left-sided renal colic, and he required a partial gastrectomy for duodenal ulcer 18 months ago. His brother has cystinuria, and several more distant maternal relations have either confirmed cystinuria or multiple renal calculi. His 24-hour cystine excretion was between 800 and 1,000 mg., and he has been given D-penicillamine for six months with no untoward side-effects.

Case 4.-A man aged 30, who started his working life as a coal-miner, developed right-sided renal colic when he was 22 and a ureteric calculus was crushed per urethram. Intravenous pylozraphy showed no evidence of renal function on the left side and there were no calculi visible. He has since had numerous episodes of right-sided renal colic necessitating five hospital admissions. He had an episode of right-sided renal colic with oliguria and uraemia three months before he was referred to this hospital. A right pyelostomy was performed and the calculus removed. The pyelostomy had been closed and his blood urea was $40 \mathrm{mg} . / 100 \mathrm{ml}$. when he came under our care. Intravenous pyelography showed that the right kidney secreted satisfactorily, and the left kidney was not visualized ; there were no calculi. His urinary cystine excretion was $1,420 \mathrm{mg} . / 24$ hours. No untoward side-effects occurred when penicillamine was given, and this patient has taken the drug under the supervision of his local hospital for six months.

Case 5.-A girl aged 16 had first passed cystine calculi when she was 4 years old. Intravenous pyelography showed bilateral renal stones. She has had repeated attacks of renal colic since then and persistent pain in the left loin recently. When admitted under our care she was tender in the left loin, and her urinary cystine excretion was $480 \mathrm{mg} . / 24$ hours. Both renal pelves contained multiple calculi, and some of the stones appeared to be in the medullary region of the kidneys. The right kidney excreted the contrast medium promptly, but excretion was delayed on the left side. She developed a faint mobilliform rash with a centripetal distribution on the ninth day of D-penicillamine treatment ; cortisone acetate (one dose of $100 \mathrm{mg}$. intramuscularly) and prednisolone $(10 \mathrm{mg}$. threehourly for five days) were given. The rash cleared, the prednisolone was slowly withdrawn, and penicillamine hydrochloride successfully restarted. A left nephrolithotomy was performed (Mr. A. W. Badenoch) and 12 cystine calculi were removed. The larger stones contained some inorganic material including calcium, but the smaller stone was pure cystine (Dr. H. E. Archer). This patient has taken D-penicillamine continuously for four months.

Case 6.-A 9-year-old boy had had repeated attacks of ureteric colic and four ureterolithotomies since he was 2 years old. The kidneys were of normal size and both renal pelves contained a calculus. He excreted $340 \mathrm{mg}$. of cystine per 24 hours and has been treated with $D$-penicillamine for four months with no untoward side-effects.

Case 7.-A girl aged 9 had had right loin pain and fever three years previously. Her right renal pelvis contained multiple calculi and the right kidney functioned poorly. A right nephrolithotomy was performed and there has been progressive impairment of function on that side. Left-sided renal colic with haematuria occurred one year before she came under our care. She passed a calculus spontaneously and her blood urea rose to $76 \mathrm{mg} . / 100 \mathrm{ml}$. during this episode although it subsequently subsided to $40 \mathrm{mg} . / 100 \mathrm{ml}$. On admission to this hospital the results of clinical and laboratory investigations were within normal limits except for a urinary cystine excretion of $460 \mathrm{mg} . / 24$ hours and urinary infection with Proteus v'ulgaris. She developed a mild diffuse morbilliform rash on the ninth day of D-penicillamine therapy. This was successfully suppressed by a single dose of cortisone acetate (75 mg. intramuscularly) and prednisolone ( $7.5 \mathrm{mg}$. by mouth every eight hours for five days). The steroid cover was slowly withdrawn and D-penicillamine therapy resumed without any further adverse effects.

\section{Effect of D-Penicillamine on Cystine Excretion}

All our cystinuric patients have shown a diminution in cystine excretion which is approximately proportional to the total daily dose of D-penicillamine (Table I). Urinary cystine levels were determined gravimetrically while the patients were in hospital, and the penicillamine dosage was increased until a satisfactory response was obtained. In our experience doses greater than $600 \mathrm{mg}$. eight-hourly may be associated with unpleasant-tasting eructation and the passage of offensive- smelling urine. Three patients developed a reaction to the drug on about the ninth day of treatment. No specific therapy was used in Case 2, but in subsequent cases the side-effects were suppressed by a short course of corticosteroid therapy and no further ill-effects were observed. The duration of prolonged therapy ranges from five months to one year (Table II). Urine analyses have been carried out at intervals during that period, and there is no evidence that the effects of the drug diminish with time. No proteinuria has developed, and the peripheral blood picture has remained normal.

TABLE II.-Effect of Long-term Penicillamine Therapy

\begin{tabular}{|c|c|c|c|c|}
\hline $\begin{array}{l}\text { Case } \\
\text { No. }\end{array}$ & $\begin{array}{l}\text { Dose of } \\
\text { Penicillamine } \\
\text { Hydrochloride }\end{array}$ & $\begin{array}{l}\text { No. of } \\
\text { Deter- } \\
\text { minations }\end{array}$ & $\begin{array}{c}\text { Overall } \\
\text { Duration of } \\
\text { Treatment }\end{array}$ & $\begin{array}{l}\text { Daily Cystine } \\
\text { Excretion } \\
\text { (mg.) }\end{array}$ \\
\hline $\begin{array}{l}3 \\
5 \\
6\end{array}$ & $\begin{array}{l}300 \mathrm{mg} .8 \text {-hrly } \\
300 \mathrm{mg} . \text { b.d. }+450 \mathrm{mg} . \text { nocte } \\
600 \mathrm{mg} \cdot 8 \text {-hrly } \\
300 \mathrm{mg} . \text { b.d. }+450 \mathrm{mg} . \text { nocte } \\
450 \mathrm{mg} .8 \text {-hrly }\end{array}$ & $\begin{array}{l}3 \\
5 \\
5 \\
1 \\
2 \\
4\end{array}$ & $\begin{array}{l}2 \text { months } \\
6 \% \\
12 \% \\
7 \% \\
5 \% \\
5 \text { ”’ }\end{array}$ & $\begin{array}{r}270 \\
130 \\
90 \\
270 \\
150 \\
250\end{array}$ \\
\hline
\end{tabular}

\section{Identification of L-Cysteine-D-Penicillamine Mixed Disulphide and of D-Penicillamine Disulphide in Urine of Cystinuric Patients Taking D-Penicillamine}

The intensity of the cystine spot on filter-paper chromatograms of the patients' urine decreased and two new spots appeared during $\mathrm{D}$-penicillamine therapy as previously described (Crawhall et al., 1963). The area of a chromatogram bearing the presumed L-cysteine-D-penicillamine disulphide was cut out, the amino-acid eluted with hydrochloric acid (approximately $1 \mathrm{~N}$ ), and the eluant removed by evaporation. The residue was oxidized with performic acid (Hirs, 1956), and the products were identical with authentic cysteic and penicillaminic acid as judged by the filter-paper chromatography.

A chromatogram prepared from a cystinuric patient's urine to which the mixed disulphide and penicillamine disulphide had been added was identical with chromatograms prepared from the same patient's urine when she was subsequently treated with D-penicillamine, except for the presence of cystine in the former case.

Ion-exchange chromatography with the Technicon automatic amino-acid analyser confirmed that D-penicillamine therapy was associated with a considerable reduction in cystine excretion, and the excretion of two new compounds whose peak effluent volumes corresponded to those of L-cysteine-Dpenicillamine mixed disulphide and $\mathrm{D}$-penicillamine disulphide respectively. The excretion of lysine, arginine, and ornithine was unaltered by D-penicillamine administration. In this method of analysis acidified urine is applied direct to the ionexchange column and the amino-acids are eluted at $\mathrm{pH} 2.87$. The high concentration of hydrogen ions eliminates the theoretical possibility that disulphide exchange might occur during the analysis.

\section{Discussion}

The determination of cystine in the presence of other disulphides presents special problems. Thus, although the urinary cystine can be measured by isotope dilution analysis, polarography (Fowler et al., 1952), ion-exchange chromatography (Brigham et al., 1960), and colorimetric analysis-for example, Hess and Sullivan (1935)when the patient is not taking penicillamine, a gravimetric procedure has proved most suitable for routine use during treatment (see Table I). The gravimetric results are confirmed by isotope dilution analysis using $\left[{ }^{35} \mathrm{~S}\right]$ cystine in the untreated patient, but considerably higher values are obtained 
by isotope dilution analysis than by gravimetric analysis when the patient is on penicillamine, possibly by exchange of the radioactive half-cystine residues with the mixed disulphide pool. Polarographic analysis using the cobalt-ammonium method does not distinguish between penicillamine disulphide and cystine (F. L. Warren, private communication). Paper chromatography can be used to demonstrate the decrease in cystine output, but these results are only semi-quantitative. Harris and Robson (1957) have shown that some relatives of cystinuric patients excrete about $200 \mathrm{mg}$. of cystine per g. creatinine. These individuals, who are presumed to be heterozygous for the cystinuria gene, do not form calculi, and therefore we did not think it necessary to reduce the cystine excretion of our patients below this level.

Clayton and Patrick (1961) used penicillamine in the treatment of cystinosis in the Lignac-de Toni-Fanconi syndrome, and reported improved growth, reduction of the blood pyruvate level, and some decrease in the generalized aminoaciduria. Subsequent studies have suggested that the excess cystine was probably acting as an enzyme inhibitor in that disease (Patrick, 1962), and it is possible that the cystine was being removed by a disulphide exchange with penicillamine. In the case of cystinuria, D-penicillamine reduced the cystine excretion but did not affect the excretion of the basic amino-acids.

The results reported in this paper confirm that it is possible substantially to reduce the urinary cystine output in cystinuria by oral administration of $\mathrm{D}$-penicillamine for periods of up to one year without any evidence of decreasing effectiveness of the treatment, and that the treatment has been free of any long-term side-effects over this period.

\section{Summary}

D-Penicillamine has been used to reduce the urinary cystine excretion in seven cystinuric patients. No effect on the excretion of the basic amino-acids was observed.

A diffuse morbilliform rash has been observed in three patients. This was controlled by steroid cover in the two patients to whom it was applied, and it was found possible to continue penicillamine therapy when the symptoms had subsided.

Most of these patients have continued on penicillamine therapy for periods ranging from a few months up to one year. No further side-effects have developed and there has been no evidence of further stone formation.

\section{REFERENCES}

Aposhian, H. V., and Aposhian, M. M. (1959). F. Pharmacol. exp. Ther., 126,131 .

Brigham, M. P., Stein, W. H., and Moore, S. (1960). F. clin. Invest., 39, 1633 .

Clarke, H. T., Johnson, J. R., and Robinson, R. (editors) (1949). Chemistry of Penicillin, p. 467. Oxford Univ. Press, London.

Clayton, B. E., and Patrick, A. D. (1961). Lancet, 2, 909.

Crawhall, J. C., Scowen, E. F., and Watts, R. W. E. (1963). Brit. med. 7., $1,588$.

Fowler, D. I., Harris, H., and Warren, F. L. (1952). Lancet, 1, 544. Goldbers A., Smith, J. A, and Lockhead, A. C. (1963). Brit. med. ₹., 1,1270 .

Harris, H., and Robson, E. B. (1957). Amer. 7. Med., 22, 774.

Hess, W. C.! and Sullivan, M. X. (1935). F. biol. Chem., 108, 195.

Hirs, C. H. W. (1956). Ibid., 219, 611.

Levine, B. B. (1960). Nature (Lond.), 187, 940

Patrick, A. D. (1962). Biochem. F., 83, 248.

Scheinberg, I. H., and Sternlieb, I. (1960). Ann. intern. Med., 53, 1151.

Walshe, J. M. (1960). Ibid., 53, 1090.

\title{
Outbreaks of a Papulo-vesicular Exanthem on the Hands and Feet ("Summer-term Blains")
}

\author{
R. P. WARIN,* M.D., F.R.C.P. ; N. S. GALBRAITH, † M.B., D.P.H. ; N. H. H. GOLLEDGE, $\ddagger$ M.R.C.S., L.R.C.P. ; \\ S. P. HALL-SMITH,§ M.D., F.R.C.P.ED., M.R.C.P. ; A. E. K. PRICE,\| T.D., M.B., B.S. ; \\ P. G. MANN, I M.D., DIP.BACT. ; H. R. E. WALLIS,** M.D., M.R.C.P.
}

Brit. med. F., 1964, 1, 1413-1416

In May 1962, at a girls' boarding-school in Bath (school A), there was an outbreak of a papulo-vesicular rash on hands and feet involving 52 pupils out of a total of 271 . Two to three weeks later a similar outbreak occurred at another girls' boarding-school 15 miles ( $24 \mathrm{~km}$.) east of Bath (school B), affecting 38 pupils out of a total of 217. In May 1962, in the Hastings area, nine girls developed the same pattern of eruption: four from one girls' boarding-school, four from another girls' boarding-school, and one from a day school. In May 1963 a further outbreak of the same condition occurred at a co-educational boarding-school 20 miles $(32 \mathrm{~km}$.) south of Bristol (school C). There were 15 cases, all in girls, although the $\mathbf{2 7 0}$ pupils consisted of boys and girls in equal numbers.

In May 1963 four girls at school A and two at school B who had suffered from the eruption in 1962 developed it again. Also

\footnotetext{
* Consultant Dermatologist, Bristol. † Epidemiologist, Central Public Health La

₹ General Practitioner, Axbridge, Somerset.

II General Practitioner, Bath.

* Consultant Paediatrician, Bath. Dr. H. R. E. Wallis died before the paper was completed.
}

at this time an isolated case occurred in another girls' boardingschool in Bath.

\section{Clinical Features}

With the exception of two staff and two girls under 12, all the cases occurred in the 12-17 age-group, affecting chiefly girls aged 13-16. The rash was confined to the hands and fingers in $67 \%$, to the feet and toes in $8 \%$, and in $25 \%$ it was on both hands and feet. It occurred mainly on the backs of the fingers and toes but also on the fronts of the fingers, the hands, the borders of the feet, and the heels. In most girls the rash comprised between 5 and 10 lesions, but in some there were up to 50 .

The lesions were between 0.5 and $3 \mathrm{~cm}$. in diameter, raised, and dark red to purple in colour with some surrounding bluish erythema. Vesicles appeared in the centre in many and reached a size of $0.5-1 \mathrm{~cm}$. in diameter (Figs. 1-3). Particularly on the fronts of the fingers and hands, the vesicles developed a grey flaccid appearance. Some of the lesions ulcerated. There was slight itching, and some were painful and tender, and where 